\title{
Специализированный биометеорологический показатель
}

\author{
В. С. Балакин, Ю. В. Шипко \\ Центральный научно-исследовательский институт \\ Военно-воздушных сил (Минобороны России), Российская Федераџия \\ (127083, г. Москва, аллея Петровско-Разумовская, 12A, стр. 4)
}

\begin{abstract}
Аннотация: Цель - совершенствование метеорологического обеспечения функционирования авиационных подразделений в районах с жарким климатом путем разработки специализированного биометеорологического показателя оценки безопасности работ персонала на открытой местности в условиях повышенных температур.

Meтоды и материалы. Модель показателя построена на основе подхода Харрингтона (обобщенной функции желательности). Информационную базу составили: данные наблюдений (1999-2018 гг.) на метеостанциях сети Росгидромета: Верхний Баскунчак, Волгоград, Астрахань, Александров Гай, Сочи; материал реанализа параметров атмосферы NCEP/DOE; ресурсы Мировых центров данных (наблюдений на метеорологических станциях территории Ближнего Востока).

Pезультаты. Построена модель специализированного биометеорологического показателя, отвечающего требованиям поддержки принятия метеозависимых решений органами управления, которая учитывает физическую нагрузку персонала и технологический период, необходимый для подготовки/ обслуживания техники. Разработан программный комплекс автоматизированного расчета показателя. Приводятся пространственные распределения показателя в различных формах. Дана оценка эффективности применения показателя.

Bblвoдbl. Использование специализированного биометеорологического показателя может способствовать совершенствованию метеорологического обеспечения авиационных подразделений в условиях жаркого климата летнего сезона (в сравнении с индексом теплового стресса WBGT применение специализированного показателя дает повышение качества на 3-8 \% - в зависимости от климатических условий района).

Ключевые слова: безопасность работ персонала, показатель теплового стресса, технологический период, функция желательности Харрингтона, автоматизированный расчет.

Для цитирования: Балакин В.С., Шипко Ю.В., Колычев О.В. Специализированный биометеорологический показатель // Вестник Воронежского государственного университета. Серия: География. Геоэкология, 2021, № 4, с. 60-68. DOI: https://doi.org/10.17308/geo.2021.4/3751
\end{abstract}

\section{ВВЕДЕНИЕ}

Авиационный персонал подразделений государственной авиации выполняет различные задачи при подготовке (обслуживании) авиационной техники на открытой местности. При базировании в районах с жарким климатом летнего сезона работа персонала в условиях высокой температуры окружающего воздуха имеет определенные ограничения, обусловленные снижением работоспособности, точности выполнения технологиче-

(C) Балакин В.С., Шипко Ю. В., Колычев О. В., 2021

凹 Шипко Юрий Владимирович, e-mail: yshipko@mail.ru ских операций и риском для здоровья. При физической нагрузке персонала в условиях работы на открытом солнце возникают отрицательные последствия, тепловые травмы [6].

В настоящее время порядок организации работ в условиях повышенных температур определяется многочисленными ГОСТами Российской Федерации и международными стандартами ISO по эргономике термальной среды, руководящими и методическими документами Госсанэпиднадзора России по вопросам гигиенического нормиро- 
вания условий труда в неблагоприятных климатических и микроклиматических условиях ${ }^{1}$. В практике метеорологического обеспечения различных потребителей используются многочисленные биометеорологические показатели (индексы) $[4,7,8]$. Однако проведенный анализ тепловых индексов показал, что они оценивают или степень комфортности климатических условий, или эргономические свойства рабочих мест в помещении, или предполагают проведение биометрических измерений в процессе работы персонала, или включают параметры (уровень солнечной радиации, температура внутри шарового термометра и др.), по которым отсутствуют средства измерений в метеорологическом подразделении.

Таким образом, известные индексы «теплового стресса» и методики нормирования условий работ персонала в термальной среде не в полной мере учитывают специфику военного потребителя, они малоинформативны для принятия управленческих решений при оценке возможности выполнения технологических процессов при обслуживании авиационной техники.

Для органов управления при планировании и проведении мероприятий необходимо иметь научно обоснованную методическую поддержку, позволяющую определить возможность безопасной работы персонала на открытой местности в условиях повышенных температур воздуха в течение заданных технологических периодов.

В целях совершенствования метеорологического обеспечения функционирования авиационных подразделений в районах с жарким климатом решается задача разработки специализированного показателя оценки безопасности работ персонала на открытой местности в условиях повышенных температур, отвечающего требованиям поддержки принятия метеозависимых решений.

Информационную базу исследования составили: данные наблюдений (1999-2018 гг.) на метео- рологических станциях сети Росгидромета: Верхний Баскунчак, Волгоград, Астрахань, Александров Гай, Сочи; материал резервного объективного анализа (реанализа) параметров атмосферы NCEP/DOE AMIP-II²; ресурсы Мировых центров данных (наблюдений на метеорологических станциях территории Ближнего Востока).

\section{МОДЕЛЬ СПЕЦИАЛИЗИРОВАННОГО ПОКАЗАТЕЛЯ}

На основе проведенного анализа используемых в практике тепловых индексов сформулированы требования к специализированному биометеорологическому показателю «военного назначения»:

- верификация к погодно-климатическим условиям южной части Европейской территории России и Ближнего Востока;

- использование входных расчетных параметров, по которым имеются средства измерений в метеорологическом подразделении;

- простота в использовании (автоматизированный расчет);

- отсутствие входных параметров, требующих непосредственной диагностики в процессе работы персонала (выделяемое человеком метаболическое тепло, ректальная температура, средневзвешенная температура кожи, частота сердечных сокращений и другие физиологические характеристики);

- учет основных факторов «теплового стресса»: температуры и относительной влажности окружающего воздуха; скорости ветра; радиационной температуры; метаболической теплоты, выделяемой телом; свойств одежды работающего персонала;

- возможность прогноза величины индекса и альтернативной оценки к принятию решения командиром на безопасные работы персонала;

- учет технологического периода (заданного времени непрерывной работы персонала, необходимого для выполнения технологических операций по подготовке/обслуживанию техники).

${ }^{1}$ ГОСТ Р 57794-2017 (ISO 7933:2004). Эргономика термальной среды. Аналитическое определение и интерпретация теплового стресса с использованием расчета прогнозируемой тепловой нагрузки.

ГОСТ Р ИСО 7243-2007 (ISO 7243:1989). Термальная среда. Расчет тепловой нагрузки на работающего человека, основанный на показателе WBGT (температура влажного шарика психрометра).

ГОСТ Р ИСО 9886-2008 (ISO 9886:2004). Эргономика. Оценка температурной нагрузки на основе физиологических измерений.

Методические рекомендации Мp 2.2.8.0017-10. Режимы труда и отдыха работающих в нагревающем микроклимате в производственном помещении и на открытой местности в теплый период года/ Утв. Главным государственным санитарным врачом Российской Федерации 28.12.2010 г.

Руководство Р 2.2.2006-05. Гигиена труда. Руководство по гигиенической оценке факторов рабочей среды и трудового процесса. Критерии и классификация условий труда. М.: Госкомсанэпиднадзор России, 2005. 142 с.

СанПиН 2.2.4.3359-16. Санитарно-эпидемиологические требования к физическим факторам на рабочих местах/ Утв. Главным государственным санитарным врачом Российской Федерации 21.06.2016. № 81 .

${ }^{2}$ NCEP/DOE AMIP II Reanalysis [Электронный pecypc]. URL: http:// www.esrl.noaa.gov/pcd/data/ gridded/data.ncep. reanalysis2.html (дата обращения: 22.05.2018).

Вестник ВГУ, Серия: География. Геоэкология, 2021, № 4, 60-68 
При построении модели показателя разрешено имеющееся противоречие: с одной стороны, безопасная работа персонала на открытой местности в жарких условиях летнего сезона должна быть ограничена временным интервалом по комплексу «ключевых» факторов теплового воздействия; с другой стороны, должен быть выдержан технологический период работ.

Используются следующие условия:

- работающий персонал акклиматизирован;

- уровень физической нагрузки 3 класса - высокое выделение метаболического тепла, в среднем 350 ккал/ч (407 Вт), что отвечает следующим нагрузкам: интенсивная работа рук и туловища; перенос тяжестей; толкание или волочение тяжелогруженых ручных тележек и др. ${ }^{3}$;

- характеристики одежды: обеспечивается коэффициент термоизоляции (0,6 clo, рубашка с длинными рукавами и брюки) и индекс влагопроницаемости согласно стандартам;

- критические значения физиологических параметров субъекта: ректальная температура (при повышенной температуре поверхности тела) не выше $39{ }^{\circ} \mathrm{C}$, частота сердечных сокращений - не более 160 ударов/мин;

- скорость ветра не превышает 2 м/с (по нормативным документам);

- входные параметры модели: метеорологические факторы - температура $\left({ }^{\circ} \mathrm{C}\right)$ и относительная влажность (\%) окружающего воздуха; технологический период $\mathrm{t}$

$$
d\left(y_{j}^{\prime}\right)=\exp \left(-\exp \left(-y_{j}^{\prime}\right)\right)
$$

где $y_{j}{ }_{j}$ - кодированное значение частного признака $y_{j}$; при кодировании используется линейная зависимость $y_{j}^{\prime}=b_{0 j}+b_{1 j} y_{j}$, где коэффициенты $b_{0 j}, b_{1 j}$ определяются заданием для двух значений параметров $y_{j}$ соответствующих значений функции желательности $d\left(y^{\prime}{ }_{j}\right)$ в интервале $[0,2 ; 0,8]$.

Функция (1) имеет базовые точки $(0,2 ; 0,37$; $0,63 ; 0,8)$, что позволяет задавать границы градаций желательности строгим образом. Обычно руководствуются интервальными диапазонами с соответствующими термами: $[0 ; 0,2]-$ «очень плохо»; $[0,2 ; 0,37]$ - «плохо»; $[0,37 ; 0,63]$ - «удов- летворительно»; $[0,63 ; 0,8]$ - «хорошо»; $[0,8 ; 1,0]$ - «очень хорошо».

Обобщенный показатель задается в виде средней геометрической [3]:

$$
D=\sqrt[p]{\prod_{j=1}^{p} d\left(y_{j}^{\prime}\right)} .
$$

В качестве частных показателей сделан выбор индексов теплового стресса, которые используются в практике метеорологического обеспечения и, главное, соответствуют приведенным выше требованиям определенными информационными аспектами. Во-первых, имеется зависимость (или спецификация) показателя и интервала непрерывной работы персонала, во-вторых, - информация о физической нагрузке при выполнении работ, в-третьих, - определена отметка (градации значений показателя) наступления критических условий для физиологического состояния персонала (в среднем).

Таким образом, модель специализированного биометеорологического показателя представляется как «свертка» нескольких частных интегральных индексов, учитывающих основные (метеорологические и физиологические) факторы «теплового стресса»:

- состояния человека при физической нагрузке в жарких условиях $\left(y_{1}\right)$, для оценки которого используется индекс приведенной температуры ${ }^{4},{ }^{\circ} \mathrm{C}$ :

$$
W D=0,85 t_{w}+0,15 t,
$$

где $t_{w}$ - температура смоченного термометра, ${ }^{\circ} \mathrm{C}$; $t$ - температура сухого термометра (температура окружающего воздуха), ${ }^{\circ} \mathrm{C}$;

- теплового ощущения человека $\left(y_{2}\right),-$ показатель эффективной температуры, ${ }^{\circ} \mathrm{C}$ [7]:

$$
E T=t-0,4(t-10)\left(1-R_{H} / 100\right),
$$

где $\mathrm{R}_{H}$ - относительная влажность воздуха, \%;

- опасности жаркой среды $\left(y_{3}\right)$, - тепловой индекс (Heat index) $)^{5},{ }^{\circ} \mathrm{F}$ :

$$
\begin{aligned}
H I= & -42,379+2,04901523 t+10,14333127 R_{H}- \\
& -0,22475541 t R_{H}-0,00683783 t^{2}- \\
& -0,05481717 R_{H}^{2}+0,00122874 t^{2} R_{H}+ \\
& +0,00085282 t R_{H}^{2}-1,99 \cdot 10^{-6} t^{2} R_{H}^{2},
\end{aligned}
$$

где $t$ - температура воздуха, ${ }^{\circ} \mathrm{F}$.

${ }^{3}$ ГОСТ Р 57794-2017 (ISO 7933:2004) Эргономика термальной среды. Аналитическое определение и интерпретация теплового стресса с использованием расчета прогнозируемой тепловой нагрузки.

ГОСТ Р ИСО 7243-2007 (ISO 7243:1989) Термальная среда. Расчет тепловой нагрузки на работающего человека, основанный на показателе WBGT (температура влажного шарика психрометра).

${ }^{4}$ Goldman R.F. Introduction to heat-related Problems in military operations [Электронный pecypc]. URL: http://www. bordeninstitute.army.mil/published_volumes/harshEnv1/Ch1_IntroductiontoHeatRelatedProblemsinMilitaryOpera.pdf (дата обращения: 12.10.2018).

${ }^{5}$ The Heat Index Equation // National Weather Service: Weather Prediction Center [Электронный pecypc]. URL: http://www.wpc. ncep.noaa.gov/html/heat-index_equation.shtml (дата обращения: 26.01.2020). 
В итоге обобщенный показатель согласно (2) представляется в виде:

$$
\begin{gathered}
D=\exp \left\{-\frac{1}{3}\left[\exp \left(-b_{01}-b_{11} y_{1}\right)+\exp \left(-b_{02}-b_{12} y_{2}\right)+\right.\right. \\
\left.\left.+\exp \left(-b_{03}-b_{13} y_{3}\right)\right]\right\},
\end{gathered}
$$

где $b_{0 j}, b_{1 j}, j=1,2,3$, определяются с учетом технологического периода $\tau$ [9].

Решающим правилом оценки биометеорологической безопасности работ персонала является условие $D\left(t, R_{H}, \tau\right)>0,37$, что соответствует формулировке по Харрингтону - условия «удовлетворительные и лучше». Полагается возможность непрерывной работы без тепловых травм (с физической нагрузкой, соответствующей выделению метаболического тепла в среднем 350 ккал/ч) на открытой местности в течение заданного периода $\tau$.

Для удобства расчетов значений специализированного показателя построены номограммы $D$ $\left(t, R_{H}, \tau\right)$ в зависимости от температуры, относительной влажности воздуха, технологических периодов [9].

Разработан программный комплекс автоматизированного расчета и территориального распределения специализированного биометеорологи-

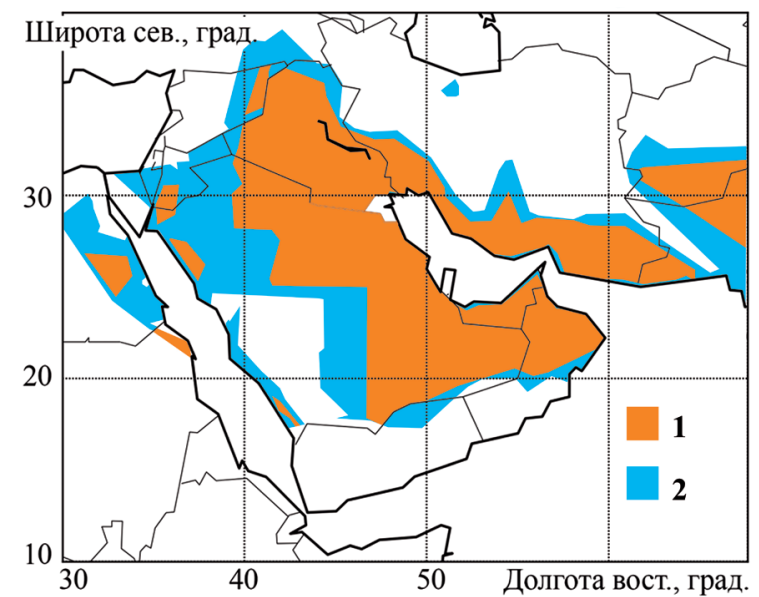

a) 10 июля 2017 г. [10.07.2017] ческого показателя $[1,2]$, программные модули которого построены с использованием языка программирования Python.

В схему расчета специализированного показателя входит процедура определения величины температуры смоченного термометра $t_{w}$, которая рассчитывается по принятому стандартом алгоритму ${ }^{6}$.

Программный комплекс включает интерфейс для взаимодействия с оператором. Входные параметры: $t_{\mathrm{BX}}, R_{H_{\mathrm{BX}}}, \tau$; выходные параметры - рекомендации к проведению работ на открытой местности при данных условиях.

\section{РАСПРЕДЕЛЕНИЯ БИОМЕТЕОРОЛОГИЧЕ- СКОГО ПОКАЗАТЕЛЯ}

C помощью автоматизированного расчета и представления специализированного показателя можно отображать на карте обстановку биометеорологической опасности работ персонала в определенный день. Например, на рисунке 1 представлены зоны опасной работы по территории Ближнего Востока (для сравнения даны условия весеннего и летнего дня, при технологических периодах $\tau=1,2$ ч).

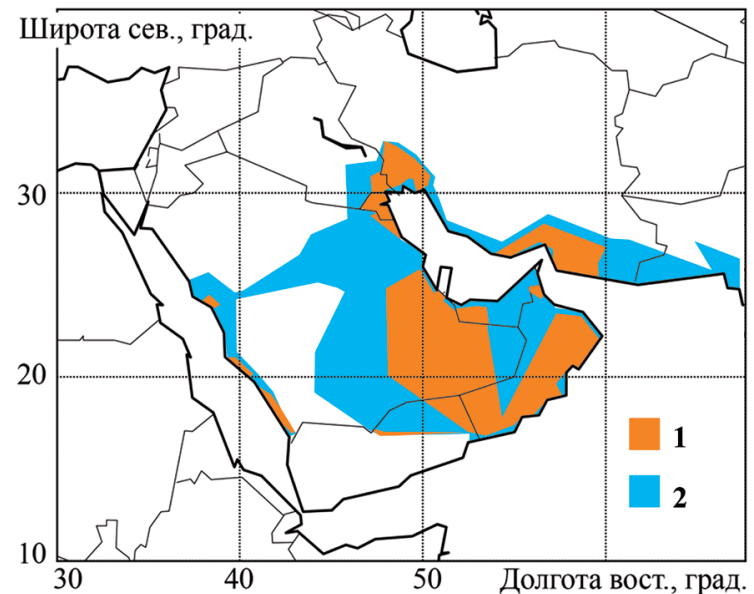

б) 20 мая 2017 г. [20.05.2017]

1 - технологический период 1 ч [ 1 -technological period $1 \mathrm{~h}]$;

2 - технологический период 2 ч $[2$ - technological period 2 h]

Puc. 1. Отображение зон опасной работы персонала (по данным метеостанций Ближнего Востока, сроки 12-18 ч)

[Fig. 1. Reflection of dangerous personnel operation zones (according to meteorological stations of the Middle East, times 12-18 h)]

Проведено районирование территории по среднему значению показателя $D$, рассчитанному по сочетаниям среднемесячных значений температуры и влажности воздуха $\left(t_{\max }, R_{H}\right) . \overline{\mathrm{Ha}}$ пример, на рисунке 2 дана картина распределения по северному полушарию среднего значения показателя $D$ для июля (технологический период $\tau=3$ ч, сроки 12,18 ч).

${ }^{6}$ ГОСТ 8.524-85 Таблицы психрометрические. Построение, содержание, расчетные соотношения 


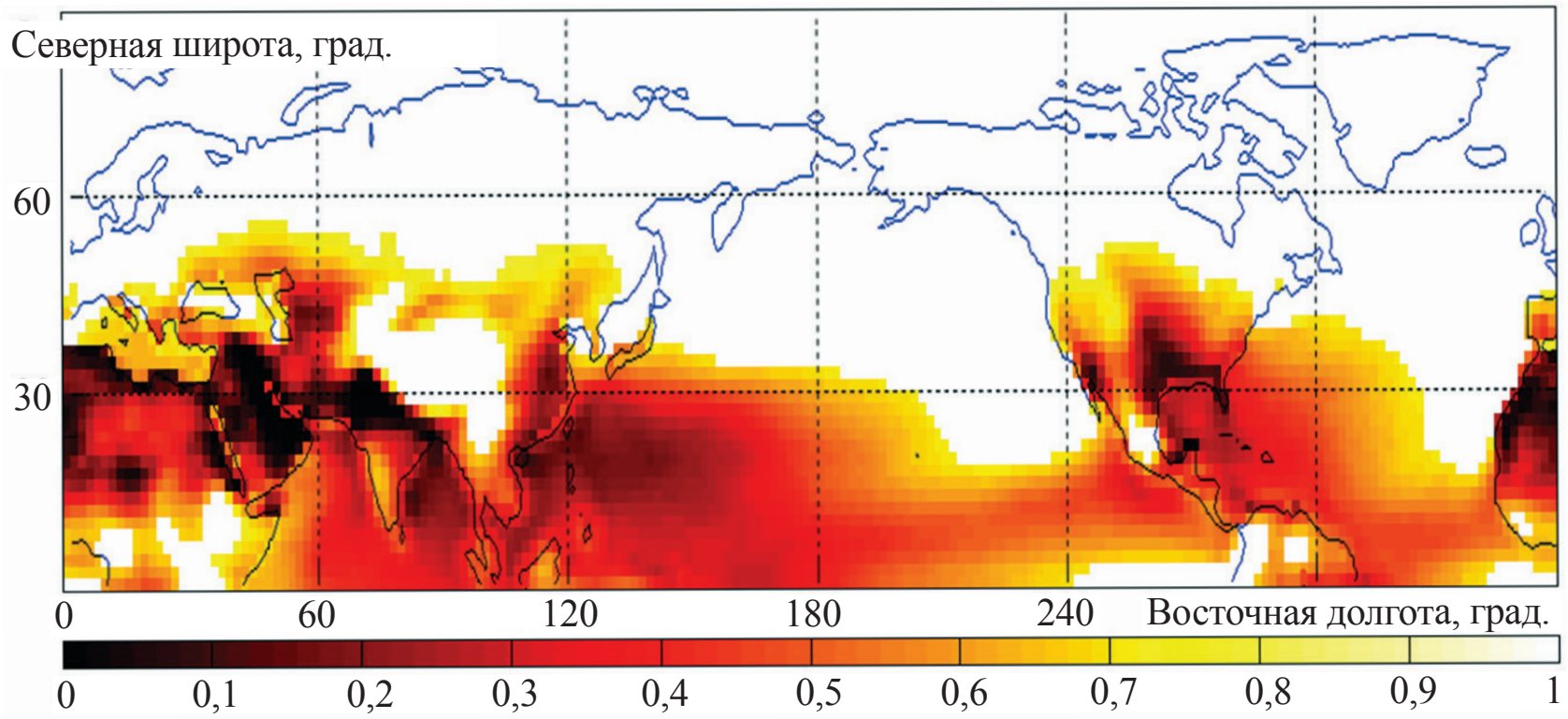

Puc. 2. Пространственное распределение по северному полушарию среднего показателя $D$ (июль, 1999-2018 гг., технологический период 3 ч)

[Fig. 2. Spatial distribution across the Northern Hemisphere of the average indicator D (July, 1999-2018, technological period 3 h)]

В отдельные дни летнего сезона картина распределения «опасных» для работ на открытой местности метеорологических условий может быть иной. Для планирования и проведения мероприятий в авиации информативным показателем может служить показатель среднего числа дней в месяце с опасными биометеорологическими условиями по району базирования. Проведен расчет специализированного показателя в такой фор- ме представления для условий районов станций южной части Европейской территории России: Верхний Баскунчак; Волгоград; Александров Гай; Астрахань; Сочи. Использовались данные наблюдений за июль 1999-2018 гг. При этом за день с опасными биометеорологическими условиями (когда $D \leq 0,37$ ) принимался такой, в течение которого данное явление отмечалось хотя бы раз из трех рассматриваемых дневных сроков (рис. 3).

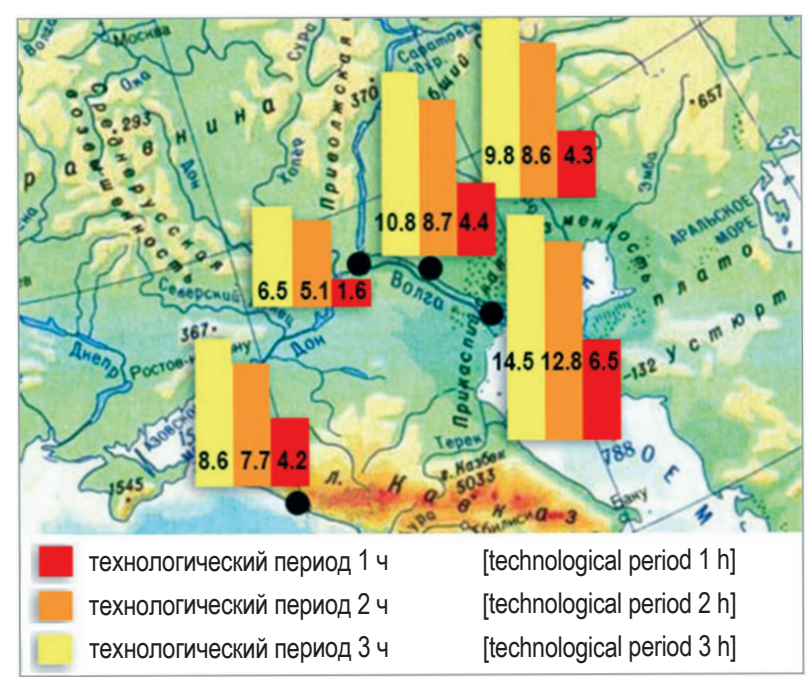

Рис. 3. Распределение среднего числа дней в июле (1999-2018 гг.)

с опасными биометеорологическими условиями для различных технологических периодов на станциях:

Верхний Баскунчак, Волгоград, Александров Гай, Астрахань, Сочи

[Fig. 3. Distribution of average number of days in July (1999-2018) with dangerous biometeorological conditions for different technological periods at stations:

Upper Baskunchak, Volgograd, Astrakhan, Alexandrov Guy, Sochi] 
Как следует из приведенных результатов (рис. 3), наиболее напряженный (с точки зрения работ на открытой местности в условиях повышенных температур) район станции Астрахань. Похожие условия наблюдаются в районах Верхний Баскунчак, Александров Гай. Несколько «лучше» условия в районе Сочи. Наименее напряженный из рассматриваемых районов - район Волгограда. Следует заметить, что среднее число дней в июле с опасными биометеорологическими условиями $(\mathrm{D} \leq 0,37)$ в отмеченных районах уменьшается с сокращением времени $\tau$ непрерывной работы персонала, поскольку для технологических периодов меньшей продолжительности возможны более жесткие метеорологические условия (по комплексу «температура, влажность»), повторяемость которых в соответствующих районах снижается (и наоборот).

\section{ОЦЕНКА ЭФФЕКТИВНОСТИ}

Проведен анализ эффективности применения разработанной методики оценки биометеорологической безопасности работающего персонала с использованием показателя относительной верификации $\gamma$, рассчитанного по численным значениям показателя эффективности J при различных стратегиях $\mathrm{S}$ обеспечения поддержки принятия метеозависимых решений [5]:

$$
\gamma^{k}=\frac{1}{N} \sum_{i=1}^{N} \frac{J_{i}\left(S^{M}\right)-J_{i}\left(S^{k}\right)}{J_{i}\left(S^{k}\right)}, \quad \forall k=\overline{1, K},
$$

где $N$ - объем архивной выборки, $S^{n}-$ методическая стратегия, основанная на использовании специализированного показателя $D, S^{k}-k$-ая эмпирическая стратегия поддержки принятия решений, $K$ - количество стратегий.

Значение показателя относительной верификации (7) позволяет судить о том, в какой степени применение стратегии $S^{n}$ по предлагаемой методике использования биометеорологической информации способствует повышению (понижению) результативности относительно другой $k$-ой методики.

В качестве $k$-ой эмпирической стратегии $S^{k}$ используются следующие подходы оценки безопасности работ на открытой местности:

1) применение ограничительного значения температуры окружающего воздуха $t=30{ }^{\circ} \mathrm{C}$ (в соответствии с требованиями Федеральных авиационных правил производства полетов государственной авиации);

2) применение индекса WBGT согласно ГОСТ Р ИСО 7243 (для открытой местности, при солнечной радиации).

В качестве критерия эффективности $J$ в формуле (7) принимается показатель числа дней в месяце, когда возможна безопасная работа персонала по обслуживанию техники на открытой местности (в дневные часы). Результаты расчетов показателя относительной верификации $\gamma^{k}$, на примере технологического периода $\tau=1$ ч, сведены в таблице 1.

Таблица 1

Значения показателя относительной верификации по выборкам для различных станций (июль, 1999-2018 гг., дневные сроки, $\tau=1$ ч)

[Table 1. Relative verification index values by samples for different stations (July, 1999-2018, daytime, $\tau=1 \mathrm{~h}$ )]

\begin{tabular}{|c|c|c|c|c|c|}
\hline \multirow{2}{*}{$\begin{array}{c}\text { Стратегия } k \\
\text { / Strategy } k\end{array}$} & $\begin{array}{c}\text { С. Баскунчак } \\
\text { / Up. Baskunchak }\end{array}$ & $\begin{array}{c}\text { Волгоград } \\
\text { / Volgograd }\end{array}$ & $\begin{array}{c}\text { Александров Гай } \\
\text { / Alexandrov Guy }\end{array}$ & $\begin{array}{c}\text { Acтрахань } \\
\text { / Astrakhan }\end{array}$ & $\begin{array}{c}\text { Сочи } \\
\text { / Sochi }\end{array}$ \\
\hline 1 & 3,13 & 1,41 & 2,51 & 2,61 & 0,08 \\
\hline 2 & 0,05 & 0,03 & 0,04 & 0,08 & 0,04 \\
\hline
\end{tabular}

Анализ данных (табл. 1) эффективности стратегии, построенной на основе методики использования показателя $D$, относительно других эмпирических стратегий, указывает на разброс значений показателя $\gamma$ в зависимости от того, с какой из эмпирических стратегий соотносится методическая стратегия, в каких климатических условиях используется. Применение специализированного показателя $D$ повышает эффективность относительно стратегии использования ограничительного критерия по температуре воз- духа $\left(t=30{ }^{\circ} \mathrm{C}\right)$ в 2,5-3 раза - для особенно жарких районов (Александров Гай, Верхний Баскунчак, Астрахань).

В сравнении с индексом теплового стресса $W B G T$ применение специализированного показателя $D$ дает повышение качества метеорологического обеспечения на 3-8 \% (в зависимости от климатических условий района).

Расчеты критерия относительной верификации $\gamma$ для сравнения методик $S^{\text {м }}$ и $S^{1}$ при временных интервалах 2 и 3 ч представлены в таблице 2. 
Таблииа 2

Значения показателя относительной верификации при различных технологических периодах

(июль, 1999-2018 гг., дневные сроки)

[Table 2. Relative verification index values at different technological periods

(July, 1999-2018, daytime)]

\begin{tabular}{|c|c|c|c|c|c|}
\hline \multirow{2}{*}{$\begin{array}{c}\text { Технологический } \\
\text { период, ч } \\
\text { / Technological } \\
\text { period, h }\end{array}$} & $\begin{array}{c}\text { В. Баскунчак } \\
\text { / Up. Baskunchak }\end{array}$ & $\begin{array}{c}\text { Волгоград } \\
\text { / Volgograd }\end{array}$ & $\begin{array}{c}\text { Александров Гай } \\
\text { / Alexandrov Guy }\end{array}$ & $\begin{array}{c}\text { Aстрахань } \\
\text { / Astrakhan }\end{array}$ & $\begin{array}{c}\text { Сочи } \\
\text { / Sochi }\end{array}$ \\
\hline 2 & 2,34 & 1,14 & 1,75 & 1,73 & $-0,02$ \\
\hline 3 & 1,92 & 1,08 & 1,68 & 1,62 & $-0,06$ \\
\hline
\end{tabular}

Относительная эффективность применения разработанной методики оценки биометеорологической безопасности (относительно методики использования обычного критерия по температуре воздуха $t=30^{\circ} \mathrm{C}$ ) значительно возрастает и при других технологических периодах для различных районов юга ЕЧР. Исключение составляет район Сочи, где использование показателя $D$ несколько снижает относительную эффективность (табл. 2). Однако следует обратить внимание, что в этом районе (на морском побережье) отмечается повышенная влажность, что усиливает нагрузку на организм работающего человека, следовательно, уменьшается число рабочих дней в месяце. Таким образом, приложение специализированного биометеорологического показателя к условиям, подобным района Сочи (с высокой климатической влажностью), снижает значения показателя относительной верификации, но учитывает безопасность персонала, работающего в таких условиях.

\section{ЗАКЛЮЧЕНИЕ}

Опыт проживания в регионах с жарким климатом позволил разработать достаточно стройную систему профилактических мер, позволяющих свести к минимуму пребывание на открытом воздухе в наиболее жаркое время суток. Широко используются технически средства, уменьшающие внешнюю тепловую нагрузку (козырьки, тенты и т. п.), перерывы в работе в дневное время, использование активных систем поддержания микроклимата в помещениях и в объектах военной техники. Однако специфика военного и авиационного труда часто вносит серьезные ограничения в использование этих средств, способов и методов. Именно в этих ситуациях возрастает роль технических средств контроля и информационной поддержки персонала.

В некоторых районах функционирования авиационных формирований природно-климатические условия летнего сезона затрудняют применение авиационной техники, снижают лет- но-технические и эксплуатационные показатели, увеличивают материальные и трудовые затраты на ее эксплуатацию, кроме того, воздействуют и на человека, работающего в таких условиях. Поэтому исследования биометеорологической безопасности персонала не теряют актуальности.

Оценка степени разработанности тематики предмета исследования указывает на то, что существующие подходы к обеспечению биометеорологической безопасности персонала при работах на открытой местности в условиях повышенных температур не всегда находятся на требуемом уровне. В первую очередь это связано со спецификой функционирования авиационных подразделений, наличием сложных связей между различными элементами системы «физиологическое состояние человека - микроклимат природных объектов».

Представленная в работе модель специализированного биометеорологического показателя оценки безопасности работ персонала на открытой местности в условиях жаркого климата (летнего сезона) отвечает требованиям поддержки принятия метеозависимых решений, учитывает временные рамки подготовки (обслуживания) техники, физическую нагрузку персонала и метеорологические условия. Использование данной модели, реализованной в виде программного комплекса автоматизированного расчета и представления специализированного показателя, может способствовать совершенствованию метеорологического обеспечения функционирования авиационных подразделений в районах базирования с жарким климатом.

\section{СПИСОК ЛИТЕРАТУРЫ}

1. Автоматизированное определение территориального распределения биоклиматического показателя безопасности работ персонала в жарком климате: Свидетельство гос. регистрации программь для ЭВМ № 2021660222 / В. С. Балакин, Ю. В. Шипко, О. В. Колычев, Н. В. Зиброва. Дата гос. регистрации в Реестре программ для ЭВМ 23 июня 2021 г. 
2. Автоматизированный расчет специиализированного биометеорологического показателя оценки безопасности работ персонала в жарком климате: Свидетельство гос. регистрации программы для ЭВМ № 2020663116/ В. С. Балакин, Ю. В. Шипко, О.В.Колычев. Дата гос. регистрации в Реестре программ для ЭВМ 22 октября 2020 г.

3. Адлер Ю.П., Маркова Е.В., Грановский Ю.В. Планирование эксперимента при поиске оптимальных условий. М.: Наука, 1976. 280 с.

4. Акимов Е. Л., Куролап С. А., Акимов Л. М. Анализ биоклиматических рисков на территории ЦЧР // Becmник Воронежского государственного университета. Серия: География. Геоэкология, 2017, № 2, с. 102-109.

5. Матвеев М.Г., Михайлов В.В. Управление организационно-технической системой в условиях метеорологической неопределенности: Монография. Воронеж: ВВВАИУ, 2006. 128 с.

6. Павлова Т.В., Сумин С.А., Шаповалов К.Г. Тeпловая травма: патоморфологические и клинические acnекты. М.: Медицинское информационное агентство, $2013.216 \mathrm{c}$
7. Руководство по специиализированному климатологическому обслуживанию экономики / Под ред. проф. Н. В. Кобышевой. СПб.: ЦНИТ «Астерион», 2008. 336 с.

8. Суковатов К. Ю., Безуглова Н.Н. Использование мультипликативной модели биоклиматического показателя для определения локальных условий безопасности работ на открытом воздухе // Вестник Воронежского государственного университета. Серия: География. Геоэкология, 2019, № 3, с. 61-66. DOI: https://doi. org/10.17308/geo.2019.3/2327

9. Шипко Ю. В., Балакин В. С., Шувакин Е. В. Обобщенный биометеорологический показатель безопасности работ на открытой местности в жарком климате // Материаль ХХ Международной научно-методической конференции «Информатика: проблемы, методы, технологии», 2020, с. 1529-1536.

Конфликт интересов: Авторы декларируют отсутствие явных и потенциальных конфликтов интересов, связанных с публикацией настоящей статьи.

Поступила в редакцию 16.12.2020 Принята к публикащии 23.11.2021

\title{
GEOECOLOGY
}

\section{Specialized Biometeorological Indicator}

\author{
V.S. Balakin, Yu.V. Shipko ${ }^{凶}$, O.V. Kolychev \\ Central Scientific Research Institute of Air Force (RF Ministry of Defense), Russian Federation \\ (4 b., 12A, Petrovsky-Razumovskaya al., Moscow, 127083)
}

Abstract: The purpose of the study is to improve the meteorological support of aviation units functioning in hot climate areas by developing a specialized biometeorological indicator to assess the safety of personnel working in open terrain in conditions of elevated temperatures.

Methods and materials. The indicator model is based on Harrington's approach (the generalized desirability function). Information base was compiled by: observation data of meteorological stations of Roshydromet network: Upper Baskunchak, Volgograd, Astrakhan, Alexandrov Guy, Sochi; reanalysis of atmospheric parameters NCEP/ DOE materials; World data Center resources (observation data of meteorological stations in the Middle East).

Results. The model of specialized biometeorological indicator that meets the requirements of supporting weather-dependent decision-making by management bodies was built. The model takes into account the physical load of personnel and the technological period necessary for the preparation/maintenance of equipment. Software package for automated calculation of the indicator is developed. The spatial distribution of this indicator in various forms is given. Efficiency of indicator application is calculated.

Conclusions. The use of the developed indicator can contribute to improving the meteorological support of aviation units in the hot climate of summer season (comparison with the heat stress index WBGT,

(C) Balakin V. S., Shipko Yu. V., Kolychev O. V., 2021

\uri V. Shipko, e-mail: yshipko@mail.ru

(c) (i) The content is available under Creative Commons Attribution 4.0 License.

Вестник ВГУ, Серия: География. Геоэкология, 2021, № 4, 60-68 
the application of specialized indicator gives an increase in quality by $3-8 \%$ depending on the climatic conditions of the area).

Key words: safety of personnel operation, heat stress index, technological period, Harrington's desirability function, automated calculation.

For citation: Balakin V.S., Shipko Yu. V., Kolychev O. V. Specialized Biometeorological Indicator. Vestnik Voronezskogo gosudarstvennogo universiteta. Seria: Geografia. Geoekologia, 2021, no. 4, pp. 60-68 (In Russ.) DOI: https://doi.org/10.17308/geo.2021.4/3751

\section{REFERENCES}

1. Avtomatizirovannoe opredelenie territorialnogo raspredeleniy bioklimaticheskogo pokazatelya bezopasnosti rabot personala $v$ zharkom klimate: Svidetel'stvo gos. registracii programmy dlya EVM № 2021660222 [Certificate of state registration of the computer program no. 2021660222]. V. S. Balakin, Yu. V. SHipko, O. V. Kolychev, N. V. Zibrova. Data gos. registracii programm dlya EVM 23 iunya 2021. (In Russ.)

2. Avtomatizirovannyj raschet specializirovannogo biometeorologicheskogo pokazatelya ocenki bezopasnosti rabot personala $v$ zharkom klimate: Svidetel'stvo gos. registracii programmy dlya EVM № 2020663116 [Certificate of state registration of the computer program no. 2020663116]. V.S. Balakin, Yu. V. SHipko, O. V. Kolychev. Data gos. registracii programm dlya EVM 22 oktyabrya 2020. (In Russ.)

3. Adler Y.P., Markova E. V., Granovskij Y. V. Planirovanie eksperimenta pri poiske optimal'nyh uslovij [Plan an experiment for optimal conditions] M.: Nauka, 1976. 280 p. (In Russ.)

4. Akimov E. L., Kurolap S.A., Akimov L. M. Analiz bioklimaticheskih riskov na territorii CCHR [Analysis of bioclimatic risks in the territory of CCR]. Vestnik Voronezhskogo gosudarstvennogo universiteta. Seria: Geografia. Geoekologia, 2017, no. 2, pp. 102-109. (In Russ.)

5. Matveev M.G., Mihajlov V.V. Upravlenie organizacionno-tekhnicheskoj sistemoj $v$ usloviyah meteorologicheskoj neopredelennosti [Management of the organizational-technical system in conditions of meteorogical uncertainty]. Monografiya. Voronezh: VVVAIU, 2006. 128 p. (In Russ.)

Балакин Владимир Станиславович

старший научный сотрудник научно-исследовательской лаборатории Центрального научно-исследовательского института Военно-воздушных сил (Минобороны России), г. Москва, Российская Федерация, ORCID: 00000002-7332-2946, e-mail: balakin69vs@gmail.com.

\section{Шипко Юрий Владимирович}

кандидат технических наук, доцент, старший научный сотрудник научно-исследовательской лаборатории Центрального научно-исследовательского института Военно-воздушных сил (Минобороны России), г. Москва, Российская Федерация, ORCID: 0000-0002-36776594, e-mail: yshipko@mail.ru.

Колычев Олег Васильевич

младший научный сотрудник научно-исследовательской лаборатории Центрального научно-исследовательского института Военно-воздушных сил Министерства обороны Российской Федерации, г. Москва, Российская Федерация, e-mail: ok.home@mail.ru.
6. Pavlova T. V., Sumin S.A., Shapovalov K. G. Teplovaya travma: pato-morfologicheskie $i$ klinicheskie aspekty [Heat injury: pathomorphological and clinical aspects]. M.: Medicinskoe informacionnoe agentstvo, 2013. 216 p. (In Russ.)

7. Rukovodstvo po specializirovannomu klimatologicheskomu obsluzhivaniyu ekonomiki [Guide to specialized climatological services for the economy]. Pod red. prof. N. V. Kobyshevoj. SPb.: CNIT «Asterion», 2008. 336 p. (In Russ.)

8. Sukovatov K.Yu., Bezuglova N.N. Ispolzovanie multiplikativnoi modeli bioklimaticheskogo pokazatelya dlya opredeleniya lokalnih uslovii bezopasnosti rabot na otkritom vozduhe [Using multiplicative bioclimatic indicator model to determine local safety conditions for work outdoors]. Vestnik Voronezhskogo gosudarstvennogo universiteta. Seria: Geografia. Geoekologia, 2019, no. 3, pp. 61-66. (in Russ.). DOI: https://doi.org/10.17308/geo.2019.3/2327

9. Shipko Yu. V., Balakin V.S., Shuvakin E. V. Obobshchennyj biometeorologicheskij pokazatel' bezopasnosti rabot na otkrytoj mestnosti v zharkom climate [Generalized biometeorological indicator of open area safety in hot climates]. Materialy XX Mezhdunarodnoj nauchno-metodicheskoj konferencii «Informatika: problemy, metody, tekhnologii», 2020, pp. 1529-1536. (In Russ.)

Conflict of interests: The authors declare no information of obvious and potential conflicts of interest related to the publication of this article.

Received: 16.12.2020

Accepted: 23.11.2021

Vladimir S. Balakin

Senior Researcher of the Scientific Research Laboratory, Central Scientific Research Institute of Air Force (RF Ministry of Defense), Moscow, Russian Federation, ORCID: 0000-0002-7332-2946, e-mail: balakin69vs@gmail.com.

Yuri V. Shipko

Cand. Sc. (Tech.), Associate Professor, Senior Researcher of the Scientific Research Laboratory, Central Scientific Research Institute of Air Force (RF Ministry of Defense), Moscow, Russian Federation, ORCID: 0000-0002-36776594, e-mail: yshipko@mail.ru

Oleg V. Kolychev

Junior Researcher of the Scientific Research Laboratory, Central Scientific Research Institute of Air Force (RF Ministry of Defense), Moscow, Russian Federation, e-mail: ok.home@mail.ru. 